\title{
Submarine deltaic geometries linked to steep, mountainous drainage basins in the northern shelf of the Alboran Sea: Filling the gaps in the spectrum of deltaic deposition
}

\author{
P. Bárcenas ${ }^{\text {a,* }}$, F.J. Lobo ${ }^{\text {b }}$, J. Macías ${ }^{\text {a }}$, L.M. Fernández-Salas ${ }^{c}$, N. López-González ${ }^{\text {d }}$, V. Díaz del Río ${ }^{\text {d }}$ \\ a Departamento de Análisis Matemático, Facultad de Ciencias, Universidad de Málaga, Campus de Teatinos s/n, 29080 Málaga, Spain \\ ${ }^{\mathrm{b}}$ Instituto Andaluz de Ciencias de la Tierra (CSIC-Universidad de Granada), Avenida de las Palmeras $n^{\circ}$ 4, 18100 Armilla, Granada, Spain \\ c Instituto Español de Oceanografía, Centro Oceanográfico de Cádiz, Muelle de Levante s/n, Apdo. 2609, 11006 Cádiz, Spain \\ d Instituto Español de Oceanografia, Centro Oceanográfico de Málaga, Puerto Pesquero s/n, 29640 Fuengirola, Spain
}

\section{A R T I C L E I N F O}

\section{Article history:}

Received 24 January 2014

Received in revised form 10 November 2014

Accepted 16 November 2014

Available online 17 December 2014

\section{Keywords:}

Alboran Sea

Shelf

Small rivers

Mountainous catchments

Submarine deltas

Geomorphology

\begin{abstract}
A B S T R A C T
A comprehensive analysis of small deltaic environments linked to short, mountainous, and seasonal fluvial systems in the northern shelf of the Alboran Sea was undertaken in order to define the controlling parameters of the geomorphological variability. The database includes multibeam and backscatter imagery, surficial sediment samples, and high-resolution seismic profiles. Additionally, geomorphological and hydrodynamic modeling and statistical analysis (principal component and cluster analysis) of hydrological and physiographic variables were performed. Most of the studied deltaic systems have high-gradient, coarse-grained deposits with preferential development of the submarine portions to the detriment of the deltaic plains. The geomorphological analysis identified three basic types of plan-view distributions according to the length-to-width ratios: elongate, linguoid and lobate. Cross-slope profiles evidence dominant concave-upward geometries, fewer occurrences of planar geometries, and no sigmoid profiles. Sediment depocenters are extremely thick in proximal locations, but thin out rapidly seawards. The geometric distribution patterns of the deltaic systems are characterized by a predictable pattern in plan-view according to the type of fluvial system, ranging from a relatively large river to ephemeral creeks. Prevailing concave and secondary planar profiles support strong sediment progradation in the submarine realm and low sediment retention in the emerged deltaic environment. Two different types of systems are distinguished: (1) larger rivers, where deltaic deposition is largely controlled by basin dimensions, ultimately dictating the magnitude of water and sediment discharges; and (2) smaller rivers and creeks, where deltaic geometries are related to the basin slopes. The influence of hydrodynamic variables on defining the submarine deltaic geometry has been observed in the case of concave-upward geometries, where geomorphological boundaries are defined by medium- and high-energy wave conditions.
\end{abstract}

(c) 2015 Elsevier B.V. All rights reserved.

\section{Introduction}

The environmental and socio-economic importance of deltaic systems has been highlighted in recent years due to growing awareness of the consequences of excessive human pressure on the coastal fringe (e.g., Bhattacharya and Giosan, 2003; Bhattacharya, 2006). In addition, the study of deltaic environments is of great interest because they represent a crucial link to understanding the interaction between fluvio-deltaic and marine sedimentation processes (Trincardi and Syvitski, 2005). As a result, several facies models and classifications have been proposed (Bhattacharya, 2006). The morphology and growth patterns of deltaic systems are controlled by a number of inter-related factors influencing the alluvial feeder system and the receiving basin, such as water discharge, sediment load, river-mouth processes, waves, tides, currents,

\footnotetext{
* Corresponding author. Tel.: + 349521320 16; fax: + 34952131894

E-mail address: pbarcenas@uma.es (P. Bárcenas).
}

winds, shelf width, and slope (Wright et al., 1974; Coleman and Wright, 1975; Orton and Reading, 1993). These factors are ultimately dependant on climate and tectonics or on a combination of both (Hart, 1995).

Deltaic deposition classifications have generally focused on the alluvial feeder system (Postma, 1990), particularly on the proximal parts (subaerial deltaic plains-delta fronts) of large recent (mostly Holocene) deltaic systems recognized in plan-view (e.g., Bhattacharya and Giosan, 2003; Bhattacharya, 2006). These subaerial parts are interpreted according to the relative significance of fluvial, tidal, and wave influences (Galloway, 1975). Furthermore, the study of submarine Holocene deltaic systems has focused on muddy shelves off large rivers (Bhattacharya, 2006), such as the modern Amazon (Nittrouer et al., 1996), the GangesBrahmaputra (Kuehl et al., 1997), and the Yellow rivers (Liu et al, 2004).

In addition, active processes and evolutionary patterns of coarsegrained fan delta systems are also reasonably well understood, particularly with regard to small-scale geomorphological and sedimentological features (e.g., Prior and Bornhold, 1990). 